\title{
The Relationship between Body Mass Index and Intra-ocular Pressure in Port Harcourt Nigeria
}

\author{
C. N. Pedro-Egbe ${ }^{1 *}$, E. A. Awoyesuku ${ }^{1}$, G. I. Nathaniel ${ }^{2}$ \\ and R. O. Komolafe ${ }^{2}$ \\ ${ }^{1}$ Department of Surgery, Ophthalmology Unit, University of Port Harcourt, Nigeria. \\ ${ }^{2}$ Department of Ophthalmology, University of Port Harcourt Teaching Hospital, Port \\ Harcourt, Nigeria.
}

\section{Authors' contributions}

This work was carried out in collaboration with other authors. Authors CNP and EAA designed the study and wrote the protocol. Authors GIN and ROK performed the literature search and all authors took part in the study. Author CNP performed the statistical analysis and wrote the first draft of the manuscript. All authors read and approved the final manuscript.

Research Article

Received $4^{\text {th }}$ December 2012

Accepted $30^{\text {th }}$ January 2013

Published $27^{\text {th }}$ February 2013

\section{ABSTRACT}

Background: There are conflicting reports regarding the relationship between body mass index (BMI) and intraocular pressure (IOP). There is a need to evaluate these contradicting findings in our environment.

Aim: To examine the relationship between intraocular pressure and body mass index (BMI) in a population screened for glaucoma at the University of Port Harcourt, Nigeria Materials and Method: This study was part of a one-day screening exercise for glaucoma at the University of Port Harcourt. All subjects participated with willful consent. Demographic data included age, sex, race and occupation. Height was measured with a wall-mounted tape and weight with a bathroom scale. Intraocular pressure was measured with Perkins hand-held applanation tonometer and funduscopy was carried out with a direct ophthalmoscope. BMI was calculated as weight in kilograms divided by the square of height in meters (Weight/Height ${ }^{2}$ ).

Results: A total of 491 subjects were screened. There were 230 males (46.8\%) and 261 females $(53.2 \%)$. About $50 \%(n=246 / 491)$ of the participants had normal BMI, 
$28.7 \%(n=141)$ were overweight while $17.7 \%(n=87)$ were obese. The mean BMI was $25.39 \pm 4.82$. Most obese participants were females $(n=63 / 87 ; 72.4 \%)$ while most males had normal body weight $(n=131 ; 53.2 \%)$. The relationship between BMI and gender was statistically significant $(P=0.00)$. The mean intraocular pressure of all participants was $16.21 \pm 5.01 \mathrm{mmHg}$. Most overweight $(88.6 \% ; n=241 / 272)$ and obese persons $(n=149 ; 87.6 \%)$ had normal IOP. There was however no statistically significant relationship between $\mathrm{BMI}$ and IOP $\left(P=0.473 ; r^{2}=0.02\right)$.

Conclusion: In a population screened for glaucoma at the University of Port Harcourt, Nigeria, we found no statistically significant relationship between BMI and intraocular pressure but there was a statistically significant relationship between BMI and age.

Keywords: BMI; intraocular pressure; relationship.

\section{INTRODUCTION}

Glaucoma is an optic neuropathy characterized by progressive degeneration of retinal ganglion cells and their axons, manifested by increasing optic disc cupping and deterioration of visual function [1]. Though, the second commonest cause of blindness in the world, [2] its etiology is not fully understood. The relationships between body mass index (BMI) and primary open angle glaucoma (POAG) are controversial. Although intraocular pressure (IOP) is no longer included in the definition of open-angle glaucoma (OAG), it remains the only modifiable and a major risk factor for the development and progression of the disease [3-4]. Some studies have reported factors such as race (African ancestry), $[5,6]$ and BMI [7-11] as associations of elevated intra-ocular pressure. Other studies which have also reported this positive association between BMI and elevated IOP include those of Lees et al., [12] Memarzadeh et al in The Los Angeles Latino Eye Study,[13] and Klein and Wu et al. respectively [14-15] It has been suggested that increased orbital pressure due to excess orbital fat may increase episcleral venous pressure and result in a decrease in outflow facility [16]. Alternatively, that the deposition of lipids has been suggested to reduce outflow facility for aqueous thereby resulting in higher IOP in obese subjects [17]. Some studies however report a tendency for glaucoma patients to have a lower BMI than control subjects [18] and in some of these studies, increased BMI appears to be a protective factor for open angle glaucoma $[19,20]$.

Although most of these listed studies on the relationship between BMI and IOP have been done in Caucasians and Asians, a community-based study on the relationship between IOP, systemic blood pressure and obesity in Port Harcourt, Nigeria, also reported no association between elevated intra-ocular pressure and obesity (Okorie UN; Part II Dissertation 2010, National Postgraduate Medical College of Nigeria, unpublished).

This study aims to examine the relationship between intra-ocular pressure and body mass index (BMI) in a population screened for glaucoma at the University of Port Harcourt, Port Harcourt, Nigeria.

\section{MATERIALS AND METHODS}

This study was part of a one-day screening exercise for glaucoma at the University of Port Harcourt, Rivers State, Nigeria. The University is located at Choba, a suburb of Port Harcourt, which is the center of the oil industry in Nigeria. The University of Port Harcourt 
Teaching Hospital Ethics Committee gave ethical approval, and all subjects participated with willful verbal consent. Demographic data included age, sex, race and occupation. Height was measured with a wall-mounted tape and weight with a bathroom scale (I.I Hanson, Ireland) with minimal clothing (no jackets on) and no shoes on. Intraocular pressure was measured with Perkins hand-held applanation tonometer (Perkins MK 2; HS Clemens Clarke International, Essex, UK) and the average of 3 readings recorded. Funduscopy was carried out with a direct ophthalmoscope (Welch Allyn Ref 11720 NY USA). BMI was calculated as weight in kilograms divided by the square of height in meters (Weight/Height ${ }^{2}$ ). Exclusion criteria included subjects who were known diabetics and hypertensives (as admitted on questioning), or those who have had some form of ocular surgeries such as cataract extraction. Data was analyzed using Epi-Info Version 6.04D and statistical significance taken as $P<0.5$.

\section{RESULTS}

A total of 491 subjects were screened. There 230 males (46.8\%), and 261 females $(53.2 \%)$ giving a male to female ratio of about 1:1.2. The mean age of the subjects was $35 \pm 13.29$ years and over $85 \%(n=431)$ of the study population was aged between 20-59 years old (Table 1).

Table 1. Age and sex distribution of the study population

\begin{tabular}{llll}
\hline Age groups (Years) & Male & Female & Total \\
\hline$<10$ & $2(0.4)$ & $3(0.6)$ & $5(1.0)$ \\
$10-19$ & $20(4.1)$ & $23(4.7)$ & $43(8.8)$ \\
$20-29$ & $70(14.3)$ & $80(16.3)$ & $150(30.5)$ \\
$30-39$ & $36(7.3)$ & $47(9.6)$ & $83(16.9)$ \\
$40-49$ & $47(9.6)$ & $78(15.9)$ & $125(25.5)$ \\
$50-59$ & $48(9.8)$ & $25(5.1)$ & $73(14.9)$ \\
$60-69$ & $6(1.2)$ & $4(1.0)$ & $10(2.0)$ \\
$70-79$ & $1(0.2)$ & $1(0.2)$ & $2(0.4)$ \\
\hline TOTAL & $\mathbf{2 3 0 ( 4 6 . 8 )}$ & $\mathbf{2 6 1 ( 5 3 . 2 )}$ & $\mathbf{4 9 1 ( 1 0 0 . 0 )}$ \\
\hline \multicolumn{4}{c}{}
\end{tabular}

Table 2 shows that most participants had normal VCDR (89.4\%). Only 102 (10.6\%) eyes had cupped discs. The mean VCDR was $0.378 \pm 0.126$. Funduscopy was not done in 16 eyes because of lens opacity. The relationship between age and VCDR is statistically significant $(P=0.03)$.

Table 2. Age groups and Cupping of the optic disc

\begin{tabular}{lllllllll}
\hline VCDR & \multicolumn{2}{l}{ Age groups } \\
\cline { 2 - 9 } & $<\mathbf{1 0 - 1 9}$ & $\mathbf{2 0 - 2 9}$ & $\mathbf{3 0 - 3 9}$ & $\mathbf{4 0 - 4 9}$ & $\mathbf{5 0 - 5 9}$ & $\mathbf{6 0 - 6 9}$ & $\mathbf{7 0 - 7 9}$ & Total\% \\
\hline Normal & 88 & 262 & 155 & 214 & 122 & 20 & 3 & $\mathbf{8 6 4}$ \\
$(\leq 0.5)$ & $(9.1)$ & $(27.12)$ & $(16.04)$ & $(22.15)$ & $(12.62)$ & $(2.07)$ & $(0.31)$ & $\mathbf{( 8 9 . 4 )}$ \\
Abnormal & 8 & 33 & 7 & 33 & 21 & 0 & 0 & $\mathbf{1 0 2}$ \\
$(>0.5)$ & $(0.8)$ & $(3.41)$ & $(0.72)$ & $(3.41)$ & $(2.17)$ & $(0.00)$ & $(0.0)$ & $(\mathbf{1 0 . 6 )}$ \\
\hline Total & $\mathbf{9 6}$ & $\mathbf{2 9 5}$ & $\mathbf{1 6 2}$ & $\mathbf{2 4 7}$ & $\mathbf{1 4 3}$ & $\mathbf{2 0}$ & $\mathbf{3}$ & $\mathbf{9 6 6}$ \\
& $\mathbf{( 9 . 9 )}$ & $\mathbf{( 3 0 . 5 )}$ & $(\mathbf{1 6 . 8 )}$ & $\mathbf{( 2 5 . 6 )}$ & $\mathbf{( 1 4 . 8 )}$ & $\mathbf{( 2 . 1 )}$ & $\mathbf{( 0 . 3 )}$ & $(\mathbf{1 0 0 . 0 )}$ \\
\hline
\end{tabular}


Table 3 shows the BMI groupings. About $28 \%(n=141)$ of the participants were overweight while $17.7 \%(n=87)$ were obese but about half of the participants however had normal body weight $(53.6 \%)$. The mean weight of the 491 participants was $69.13 \pm 14.18 \mathrm{~kg}$ and the mean height was $1.65 \pm 0.11$ meters. The mean BMI was $25.39 \pm 4.82 \mathrm{~kg} / \mathrm{m}^{2}$

Table 3. BMI Categories

\begin{tabular}{lc}
\hline BMI $\left(\mathbf{k g} / \mathbf{m}^{2}\right.$ ) categories & Frequency $\mathbf{~ \% )}$ \\
\hline$<18.5$ (Under Weight) & $17(3.5)$ \\
$18.5-24.9$ (Normal) & $246(50.1)$ \\
$25-29.0$ (Over Weight) & $141(28.7)$ \\
$\geq 30.0$ (Obesity) & $87(17.7)$ \\
TOTAL & $491(100.0)$ \\
\hline
\end{tabular}

Table 4 shows BMI according to age groupings. Most of the obese persons ( $n=76 ; 87.4 \%$ ) were aged between 30-59 years old while most participants with normal weight $(n=148 / 246)$ were in the 10-29 year group. No participant in the 50-79 year age group was underweight and none was overweight in the 10-19 year age group. The relationship between BMI and age was statistically significant $(\boldsymbol{P}=\mathbf{0 . 0 0})$

Table 4. BMI Categories by Age Groups

\begin{tabular}{lllllllll}
\hline BMI total & \multicolumn{6}{l}{ Age groups (Years) } \\
\hline & $<\mathbf{1 0 - 1 9}$ & $\mathbf{2 0 - 2 9}$ & $\mathbf{3 0 - 3 9}$ & $\mathbf{4 0 - 4 9}$ & $\mathbf{5 0 - 5 9}$ & $\mathbf{6 0 - 6 9}$ & $\mathbf{7 0 - 7 9}$ & \\
\hline $\begin{array}{l}<18.5 \\
\text { (Underweight) }\end{array}$ & $9(1.8)$ & $5(1.0)$ & $1(0.2)$ & $2(0.4)$ & $0(0.0)$ & $0(0.0)$ & $0(0.0)$ & $17(3.5)$ \\
$\begin{array}{l}18.5-24.9 \\
\text { (Normal) }\end{array}$ & $35(7.1)$ & $114(23.2)$ & $34(6.9)$ & $34(6.9)$ & $25(5.1)$ & $3(0.6)$ & $1(0.2)$ & $246(50.1)$ \\
$\begin{array}{l}25-29.0 \\
\text { (Overweight) }\end{array}$ & $4(0.8)$ & $24(4.9)$ & $31(6.3)$ & $49(10.0)$ & $29(5.9)$ & $3(0.6)$ & $1(0.2)$ & $141(28.7)$ \\
$\begin{array}{l}\geq 30.0 \\
\text { (Obesity) }\end{array}$ & $0(0.0)$ & $7(1.4)$ & $17(3.5)$ & $40(8.1)$ & $19(3.9)$ & $4(0.8)$ & $0(0.0)$ & $87(17.7)$ \\
\hline Total & $48(9.8)$ & $150(30.5)$ & $83(16.9)$ & $125(25.5)$ & $73(14.4)$ & $10(2.0)$ & $2(0.4)$ & $491(100)$ \\
\hline
\end{tabular}

${ }^{*}$ Significant $;$ Chi square $=214.97 ; P=0.00$ *

Table 5 shows the relationship between BMI and gender. Most obese participants were females ( $n=63 / 87 ; 72.4 \%)$. Over $28 \%$ of the participants were overweight and there was not much difference between the males and females $(n=69: 72)$. Most males however had normal body weight $(n=131 ; 53.2 \%)$. The relationship between BMI and gender was statistically significant $(P=0.00)$

Table 5. BMI according to Gender

\begin{tabular}{llll}
\hline BMI category & \multicolumn{2}{l}{ Gender } & \multicolumn{2}{c}{ Total (\%) } \\
\cline { 2 - 3 } & Male (\%) & Female (\%) & \\
\hline$<18.5$ (Underweight) & $6(1.2)$ & $11(2.3)$ & $17(3.5)$ \\
$18.5-24.9$ (Normal) & $131(26.7)$ & $115(23.4)$ & $246(50.1)$ \\
$25-29.0$ (Overweight) & $69(14.0)$ & $72(14.7)$ & $141(28.7)$ \\
$\geq 30.0$ (Obesity) & $24(4.9)$ & $63(12.8)$ & $87(17.7)$
\end{tabular}




\begin{tabular}{lcc}
$230(46.8)$ & $261(53.2)$ & $491(100)$ \\
\hline
\end{tabular}

Table 6 and 7 show BMI in relation to intraocular pressure. The mean intraocular pressure of all participants was $16.21 \pm 5.01 \mathrm{mmHg}$. Most obese persons $(n=149 ; 87.6 \%)$ had normal IOP. The same goes for overweight participants, where $88.6 \% \quad(n=241 / 272)$ had normal intraocular pressures. There was no statistically significant relationship between $\mathrm{BMI}$ and IOP $\left(P=0.47 ; \mathrm{R}^{2}=0.02\right)$.

Table 6. BMI in relation to IOP

\begin{tabular}{llll}
\hline BMI Category & IOP & No (\%) & Total (\%) \\
& Normal $(\leq \mathbf{2 1} \mathbf{m m H g})$ & Abnormal (>21 mmHg) & \\
\hline$<18.5$ (Underweight) & $25(2.7)$ & $1(0.1)$ & $26(2.8)$ \\
18.5-24.9 (Normal) & $416(44.8)$ & $44(4.7)$ & $460(49.6)$ \\
$25-29.0$ (Overweight) & $241(26.0)$ & $31(3.3)$ & $272(29.3)$ \\
$\geq 30.0$ (Obesity) & $149(16.0)$ & $21(2.3)$ & $170(18.3)$ \\
TOTAL & $831(89.5)$ & $97(10.5)$ & $928(100.0)$ \\
\hline
\end{tabular}

${ }^{*}$ Not Significant; Chi square $=2.51 ; P=0.47^{*}$

Table 7. Correlation of BMI and IOP

\begin{tabular}{lll}
\hline & & IOP \\
\hline BMI & The Pearson correlation coefficient, $r$ & 0.12 \\
$\mathrm{R}^{2}$ & 0.02 \\
\hline & $R^{2}=0.02$ (showing that only $2 \%$ of the BMI values are related to IOP) &
\end{tabular}

\section{DISCUSSION}

In this population-based study of participants at a glaucoma screening exercise in Port Harcourt, Nigeria, we found no association between body mass index and elevated intraocular pressure as there was no statistically significant relationship between the two $(P=0.47)$. Those aged between 30-59 years old had the highest intraocular pressure values compared to those aged 60 years and above whose IOPs were normal. This was however not statistically significant. Most of the participants had normal BMI. Of the participants that were obese, over $72 \%$ were females. Most participants who were either overweight $(86.6 \%)$ or obese $(87.6 \%)$ had normal intraocular pressures. Our finding tends to agree with most other studies that have reported no such association including the one by Okorie UN in Port Harcourt, Nigeria. Our result is surprisingly similar to hers even though the population studied is different. Her population was those aged 40-90 years while ours was a crosssectional study. Incidentally, the study by Mori et al was cross-sectional and they reported a significant association between IOP and obesity in both cross-sectional and longitudinal analysis. Their findings also suggested that obesity was an independent risk factor for increase in IOP. Our results may have differed from that of Mori et al because of their larger sample size $(n=70,139)$ compared to ours. A larger sample size is more likely to detect statistical significance than a smaller one.

The Rotherdam Eye Study reported a 7\% reduction in the risk of developing OAG for each unit increase in BMI in women, but no significant effect in men. This association between $\mathrm{BMI}$ and primary OAG in women is attributed to declining estrogen levels with age [21]. Declining estrogen levels is important in the pathogenesis of POAG in women. Heavier 
women have higher estrogen levels, and this may be protective as has been demonstrated in animal models of glaucoma where estrogen is found to have neuro-protective effects [21]. The pathogenesis for this positive relationship has been suggested to be due to excess orbital fat, which may increase episcleral venous pressure, reduce outflow facility and cause a rise in IOP [16]. Alternatively, the deposition of lipids in obesity has been suggested to reduce outflow facility [17]. Our result however, differs from most other reported studies where there is a positive relationship between obesity and elevated IOP [7-17]. Most of these studies were done in Asians, Caucasians and Latinos [7-17], while ours is an all black population and this may have accounted for the difference in results. No reason is immediately apparent for this inverse relationship between BMI and IOP noted in our study. There is therefore the need for further studies involving a larger sample size before reasonable conclusions can be drawn from this study.

\section{CONCLUSION}

In a population screened for glaucoma at the University of Port Harcourt, the authors found a statistically significant relationship between BMI and age but no statistically significant relationship between BMI and Intra-ocular pressure. This may be because of the small sample size. We therefore need further studies involving a larger sample size before reasonable conclusions are drawn.

\section{CONSENT FORM}

Since this was a glaucoma screening exercise, individuals walked in freely to be screened. Therefore, willful verbal consent was obtained from all participants. This was stated in the section on materials and methods.

\section{ETHICAL CLEARANCE}

The University of Port Harcourt Teaching Hospital was informed of the glaucoma screening exercise in the neighboring university community and approval was given for the exercise to go on. Ethical clearance does not therefore apply here.

\section{COMPETING INTERESTS}

Authors have declared that no competing interests exist.

\section{REFERENCES}

1. Kwon $\mathrm{YH}$, Fingert JH, Kuehn $\mathrm{MH}$, Alward WL. Primary open-angle glaucoma. N Engl $\mathrm{J}$ Med. 2009;360:1113-24.

2. Quigley HA, Broman AT. The number of people with glaucoma worldwide in 2010 and 2020. Br J Ophthalmol. 2006;90(3):262-67.

3. Leske MC. The epidemiology of open-angle glaucoma: a review. Am J Epidemiol. 1983;118(2):166-91.

4. Sommer A. Intraocular pressure and glaucoma. Am J Ophthalmol. 1989;107(2):18688.

5. Klein BE, Klein R, Linton KL. Intraocular pressure in an American community. The Beaver Dam Eye Study. Invest Ophthalmol Vis Sci. 1992;33:2224-28. 
6. Shiose $Y$, Kawase $Y$. A new approach to stratified normal intraocular pressure in a general population. Am J Ophthalmol. 1986;101(6):714-21.

7. Hennis A, Wu SY, Nemesure B, Leske MC. Hypertension, diabetes, and longitudinal changes in intraocular pressure. Ophthalmology. 2003;110(5): 908-14.

8. Bulpitt CJ, Hodes C, Everitt MG. Intraocular pressure and systemic blood pressure in the elderly. Br J Ophthalmol. 1975;59(12):717-20

9. Wu SY, Leske MC. Associations with intraocular pressure in the Barbados Eye Study. Arch Ophthalmol. 1997;115(12):1572-76.

10. Mori K, Ando F, Nomura H, Sato $\mathrm{Y}$, Shimokata $\mathrm{H}$. Relationship between intraocular pressure and obesity in Japan. Int J Epidemiol. 2000;29:661-66.

11. Zheng H, Cheung CYL, Tien Y, Wong TY, Mitchell P, Aung T. Influence of height, weight, and Body Mass Index on optic disc parameters. Invest. Ophthalmol. Vis. Sci. 2010;51(6):2998-3002.

12. Lee JS, Lee SH, Oum BS, Chung JS, Cho BM, Hong JW. Relationship between intraocular pressure and systemic health parameters in a Korean population. Clin Experiment Ophthalmol. 2002;30(4):237-41.

13. Memarzadeh F, Ying-Lai M, Azen PS, Varma R. Associations with Intraocular Pressure in Latinos: The Los Angeles Latino Eye Study. Am J Ophthalmol. 2008;146(1):69-76.

14. Klein BE, Klein R, Linton KL. Intraocular pressure in an American community. The Beaver Dam Eye Study. Invest Ophthalmol Vis Sci. 1992(7);33:2224-28.

15. Wu SY, Leske MC. Associations with intraocular pressure in the Barbados Eye Study. Arch Ophthalmol. 1997;115(12):1572-76.

16. Shiose $Y$, Kawase $Y$. A new approach to stratified normal intraocular pressure in a general population. Am J Ophthalmol. 1986;101(6):714-21.

17. Bulpitt CJ, Hodes C, Everitt MG. Intraocular pressure and systemic blood pressure in the elderly. Br J Ophthalmol. 1975;59(12):717-20

18. Gasser P, Stumpfig D, Schotzau A, Ackermann-Liebrich U, Flammer J. Body mass index in glaucoma. J Glaucoma. 1999;8(1):8-11.

19. Leske MC, Connell AM, Wu SY, Hyman LG, Schachat AP. Risk factors for open-angle glaucoma: The Barbados Eye Study. Arch Ophthalmol. 1995;113(7):918-24.

20. Cheung N, Wong TY. Obesity and eye diseases. Surv Ophthalmol. 2007;52(2):18095.

21. Ramdas WD, Wolfs RC, Hofman A, de Jong PT, Vingerling JR, Jansonius NM. Lifestyle and risk of developing Open-Angle glaucoma. Arch Ophthalmol. 2011;129(6):767-72.

(C) 2013 Pedro-Egbe et al.; This is an Open Access article distributed under the terms of the Creative Commons Attribution License (http://creativecommons.org/licenses/by/3.0), which permits unrestricted use, distribution, and reproduction in any medium, provided the original work is properly cited.

Peer-review history:

The peer review history for this paper can be accessed here: http://www.sciencedomain.org/review-history. php?iid=194\&id=12\&aid=992 